\title{
IgM-mediated autoimmune responses to oxidative specific epitopes, but not nitrosylated adducts, are significantly decreased in pregnancy: association with bacterial translocation, perinatal and lifetime major depression and the tryptophan catabolite (TRYCAT) pathway
}

\author{
Chutima Roomruangwong ${ }^{1}$ - Buranee Kanchanatawan ${ }^{1}$ - Sunee Sirivichayakul ${ }^{2}$. \\ George Anderson $^{3}$ • André F. Carvalho ${ }^{4}$ - Sebastien Duleu ${ }^{5}$ - Michel Geffard ${ }^{5,6}$. \\ Michael Maes ${ }^{1,7,8,9,10}$
}

Received: 7 January 2017 / Accepted: 24 May 2017

(C) Springer Science+Business Media New York 2017

\begin{abstract}
Immunoglubulin (Ig)M responses directed to oxidative specific epitopes (OSEs) and nitric oxide (NO)-adducts are significantly associated with major depression and physiosomatic symptoms. End of term serum IgM responses to OSEs and NO-adducts were assayed in pregnant women with $(n=24)$ and without prenatal depression $(n=25)$ as well as in 24 nonpregnant women. Associations of IgM/IgA responses to Gramnegative gut commensal bacteria (leaky gut index) and IgA/IgM responses to tryptophan catabolites (TRYCATs) were analyzed.
\end{abstract}

\section{Michael Maes}

dr.michaelmaes@hotmail.com; http://scholar.google.co.th/

citations?user=1 wzMZ7UAAAAJ \&hl=th\&oi=ao

1 Department of Psychiatry, Faculty of Medicine, Chulalongkorn University, Bangkok, Thailand

2 Department of Medicine, Faculty of Medicine, Chulalongkorn University, Bangkok, Thailand

3 CRC Scotland \& London, London, UK

4 Department of Clinical Medicine and Translational Psychiatry Research Group, Faculty of Medicine, Federal University of Ceará, Fortaleza, CE, Brazil

5 Research Department, IDRPHT, Talence, France

6 GEMAC, Lieu-Dit Berganton, Saint Jean d‘Illac, France

7 Department of Psychiatry, Faculty of Medicine, State University of Londrina, Londrina, Brazil

8 Department of Psychiatry, Medical University Plovdiv, Plovdiv, Bulgaria

9 Revitalis, Waalre, The Netherlands

10 IMPACT Research Center, Barwon Health, Deakin University, Geelong, VIC, Australia
IgM responses to OSEs, but not NO-adducts, were significantly reduced at the end of term. There were no significant associations between IgM responses to OSEs and perinatal depression, whilst IgM responses to NO-adducts, especially NO-cysteinyl, were significantly associated with a lifetime major depression. IgM responses to OSEs and NO-cysteinyl were significantly associated with $\operatorname{Ig} \mathrm{A} / \mathrm{IgM}$ responses to Gram-negative bacteria, especially Morganella morganii, Klebsiella pneumoniae and Citrobacter koseri. IgM responses to NO-adducts and OSEs, especially malondialdehyde and myristic acid, and C-reactive protein (CRP) were inversely associated with TRYCAT pathway activity, whilst a lifetime depression and Pseudomonas putida were positively associated. The attenuation of natural IgM-mediated responses to OSEs at the end of term may indicate lowered activity of this part of the compensatory (anti-)inflammatory reflex system and may be partly explained by lowered bacterial translocation. Increased IgM responses to NO-cysteinyl is a biomarker of lifetime depression and may be induced by bacterial translocation. Natural IgM-mediated autoimmune responses, increased nitrosylation and higher CRP levels may have negative regulatory effects on the TRYCAT pathway.

Keywords Depression · Inflammation · Immune · Kynurenine $\cdot$ Cytokines $\cdot$ Compensatory (anti-)inflammatory reflex system (CIRS)

\section{Introduction}

Clinical depression is accompanied by increased peripheral immune-inflammation coupled to increased levels of oxidative 
and nitrosative stress (IO\&NS), as indicated by raised levels of acute phase proteins, such as C-reactive protein (CRP), proinflammatory cytokines, oxidative stress biomarkers and signs of hypernitrosylation (Anderson and Maes 2014). The immune picture in depression shows increased levels of M1 macrophage cytokines, including interleukin (IL)-1 $\beta$, IL-6 and tumor necrosis factor (TNF)- $\alpha$ as well as Th1 cytokines, including interferon (IFN)- $\gamma$ (Eyre et al. 2013; Maes et al. 2012a, b; Miller et al. 2009). Increased levels of oxidative stress in depression is indicated by damage to cell membranes, lipids, proteins and DNA (Anderson and Maes 2016; Czarny et al. 2016). Increased levels of malondialdehyde (MDA), a toxic product of polyunsaturated lipids degradation following damage by reactive oxygen species (Pryor and Stanley 1975), is one of the most frequently observed biomarkers in unipolar and bipolar depression (Del Rio et al. 2005; Pryor and Stanley 1975).

Major depression, and especially when chronic, is accompanied by increased immunoglobulin (Ig)M-mediated autoimmune responses against oxidative specific epitopes (OSEs), including MDA, azelaic acid (Maes et al. 2013a, b; Maes et al. 2013a, b; Zheng et al. 2013), phosphatidyl inositol (Pi), and the anchorage molecules, myristic acid, palmitic acid and farnesylcysteine (Maes et al. 2011a, b; Maes et al. 2012a, b), indicating oxidative damage to membranes and a consequent IgMmediated natural or regulatory autoimmune response. This IgM response may aid in the clearance of oxidatively damaged, apoptotic or dying cells expressing OSE markers, including MDA (Maes et al. 2011a, b; Maes et al. 2013a, b; Maes et al. 2013a, b; Maes et al. 2011a, b; Maes et al. 2012a, b; Tsuboi et al. 2013; Zheng et al. 2013). These natural IgM antibodies not only recognize neoantigens, including OSEs, but also foreign antigens, including invading pathogens (Kanchanatawan et al. 2017; Schwartz-Albiez et al. 2009). As such, natural IgM antibodies target OSEs thereby attenuating proinflammatory responses and comprise a first-line defence against pathogens.

Clinical depression is accompanied by enhanced levels of inducible NO synthase (iNOS), NO and NO metabolites and increased nitrosation and nitrosylation of proteins (Gałecki et al. 2012; Maes et al. 2013a, b, 2011a, b; Morris et al. $2016 \mathrm{a}, \mathrm{b})$. Increased autoimmune responses to NO-adducts have been observed in depression, and especially when chronic, indicating hypernitrosylation (Maes et al. 2013b; 2011a). Nitrosylation may have a regulatory role; for example, it may aid in DNA repair mechanisms, whilst hypernitrosylation may lead to deleterious and neurodegenerative effects (Morris et al. $2016 \mathrm{a}, \mathrm{b})$. In addition, some IgM-mediated autoimmune responses to NO-adducts are detrimental and neurotoxic, including increased IgM responses to NO-cysteinyl (Morris et al. 2016a, b; Moylan et al. 2014). No studies have examined these IgM responses to OSEs and NO-adducts during pregnancy or in prenatal depression.

Th1 cytokines, especially IFN- $\gamma$, M1 macrophage cytokines and oxidative stress activate indoleamine 2,3-dioxygenase, which drives tryptophan to the production of tryptophan catabolites (TRYCATs), including quinolinic, picolinic and xanthurenic acid, kunurenine and 3-OH-kynurenine (Anderson et al. 2014a, b; Martin-Subero et al. 2016; Morris et al. 2016a, b). Research projects are being performed to clarify as to whether TRYCAT pathway activation is a characteristic of depression per se or physio-somatic (formerly psycho-somatic) that often accompany clinical depression (Anderson et al. 2014a, b). Recently, we found no significant differences in TRYCAT levels in association with perinatal depression, although increased TRYCAT levels were associated with physio-somatic symptoms at the end of term (Maes et al. 2008). To date, no previous studies have investigated associations between TRYCAT pathway activation and IgM-mediated immune responses to OSEs and nitrosylation in perinatal depression.

Increased gut permeability followed by increased bacterial translocation (leaky gut) is another condition that may be associated with clinical depression, especially when chronic (Maes et al. 2008). This condition is indicated by increased serum IgM / IgA responses directed against antigens and LPS of Gram-negative bacteria, including Hafnia alvei, Pseudomonas aeruginosa, Morganella morganii, Pseudomonas putida, Citrobacter koseri and Klebsiella pneumoniae (Roomruangwong et al. 2016). Bacterial translocation may drive gut-derived inflammation and oxidative stress as well as IgM-mediated autoimmune responses to OSEs and NO-adducts (Anderson et al. 2014a, b; Maes et al. 2013a, b). However, no studies have investigated possible associations between bacterial translocation and IgMmediated autoimmune responses in the perinatal period.

The aims of the current study are: 1) to assess whether prenatal depression is accompanied by alterations in serum IgM responses to OSEs and NO-adducts and whether there are any changes in these autoimmune responses during pregnancy; and 2) delineate the associations between these IgMmediated autoimmune responses and $\operatorname{IgM} / \operatorname{IgA}$ responses to gut commensal bacteria and TRYCAT pathway activation.

\section{Subjects and methods}

\section{Participants}

Seventy-three participants were recruited, comprised of 24 nonpregnant women and 49 pregnant women who attended the Antenatal Clinic of the King Chulalongkorn Memorial Hospital, Bangkok, Thailand. Inclusion criteria for pregnant women were: a) having planned to give birth and attend postpartum follow ups at the Department of Gynecology, King Chulalongkorn Memorial Hospital; b) 18 years of age or older; and c) being able to read and write Thai language. Exclusion criteria for pregnant women were: a) axis 1 disorders other than bipolar disorder and major depressive disorder, including autism 
and schizophrenia; b) positive VDRL or HIV serology; and c) medical or obstetric condition(s) that impede ability to complete the questionnaires. Exclusion criteria for normal controls were current and lifetime diagnoses of any axis 1 disorders. Exclusion criteria for non-pregnant and pregnant women were medical disorders, including immune and autoimmune disorders, hypertension and diabetes. The study was approved by the Ethics Committee of the Faculty of Medicine, Chulalongkorn University, Bangkok, Thailand (IRB No.321/57, COA No. $615 / 2014)$. Written informed consent was obtained from all participants.

\section{Measures}

\section{Clinical assessments}

Pregnant women were evaluated by a senior gynecologist and psychiatrist at 2 time points, namely end of term (T1) and 4 6 weeks after delivery (T2). All non-pregnant women and pregnant women were assessed using a structured interview, including the Edinburgh Postnatal Depression Scale (EPDS), Thai validated translation (Pitanupong et al. 2007; Vacharaporn et al. 2003) and Spielberger's State-Trait Anxiety Inventory (STAI), state version in a Thai validated translation (Spielberger and Vagg 1984; Thapinta 1991) Pregnant women with an EPDS score $\geq 11$ were diagnosed as suffering from depression, either antenatal (T1) or postpartum (T2) (Pitanupong et al. 2007; Vacharaporn et al. 2003). The STAI had been used to assess anxiety among pregnant women (Abedian et al. 2015; Bayrampour et al. 2015). In nonpregnant women and pregnant women at T1 we used the Mini International Neuropsychiatric Interview (M.I.N.I) - Thai version (Kittirattanapaiboon and Khamwongpin 2005) - to assess the diagnosis of "a life time history of mood disorders" (namely major depressive disorder, bipolar disorder or dysthymia) and "a life time history of depression" (namely major depressive disorder or dysthymia). At T1, all participants completed a questionnaire to obtain socio-demographic, medical and obstetric information. Body height (in m) was assessed with a manual height measure instrument and body weight in kilograms $(\mathrm{kg})$ with a digital weighing scale. Body mass index (BMI) was calculated using the formula: $\mathrm{BMI}=$ body weight $(\mathrm{kg}) /$ height $(\mathrm{m})^{2}$. The senior psychiatrist also assessed premenstrual syndrome (PMS), namely a recurrent pattern of physio-somatic symptoms (body aches, tender breasts, fatigue, bloating) and mood symptoms (depression and anxiety symptoms, tension and irritability, decreased concentration), appearing after ovulation in the luteal phase and resolving with menstruation.

\section{Assays of IgM responses directed to OSES}

At 8.00 a.m., after an overnight fast, blood was sampled in non-pregnant and pregnant woment (at T1) for the assay of
IgM-mediated autoimmune responses directed against OSEs and $\mathrm{NO}$-adducts, $\operatorname{Ig} \mathrm{A} / \mathrm{IgM}$ responses directed against antigens/LPS of Gram-negative bacteria and TRYCATs, and serum CRP. An enzyme-linked immunosorbent assay (ELISA) was used to measure IgM levels directed against conjugated azelaic acid, MDA, phosphatidylinositol (Pi) and three conjugated anchorage molecules, namely palmitic acid, myristic acid and farnesyl cysteine (Boullerne et al. 1996; Geffard et al. 2003, 2002). Azelaic acid, myristic acid, palmitic acid and farnesyl cysteine, were linked to free fatty acid BSA. Ten $\mathrm{mg}$ of each hapten was dissolved in $2 \mathrm{ml}$ of methanol containing $40 \mu \mathrm{l}$ of triethylamine (TEA). For each coupling, $20 \mathrm{mg}$ of free fatty acid BSA was dissolved in $2 \mathrm{ml}$ of water containing $40 \mu \mathrm{l}$ TEA. The carboxylic group of each hapten was activated by ethylchloroformate (ECF) diluted in DMSO. After $10 \mathrm{~min}$, BSA solutions were slowly mixed with the activated hapten solutions. After the coupling, each conjugate was purified by dialysis against phosphate buffer with $10^{3} \mathrm{M} \mathrm{CaCl} 2$. Phospatidylinositol (Pi) was linked to BSA, as described for conjugated TRYCATs (see below). MDA was linked to BSA using the following protocol: $5.280 \mathrm{ml}$ of MDA was mixed with $720 \mu \mathrm{l}$ of $4 \mathrm{~N} \mathrm{HCL}$ in $20 \mathrm{ml}$ of water. After $10 \mathrm{~min}$ stirring at $37^{\circ} \mathrm{C}$, this solution was mixed in $20 \mathrm{ml}$ of water containing $200 \mu \mathrm{l}$ of BSA. The $\mathrm{pH}$ was adjusted at 7 during $2 \mathrm{~h}$ at $37^{\circ} \mathrm{C}$. Then, the mixture was purified by dialysis with stirring water. Polystyrene 96-well plates (NUNC) were coated with $200 \mu$ l solution containing the conjugate at $10 \mu \mathrm{g} /$ $\mathrm{ml}$ for $\mathrm{Pi}$, azelaic, palmitic and myristic acids and at $80 \mu \mathrm{g} / \mathrm{mL}$ for MDA in $0.05 \mathrm{M}$ carbonate buffer at $\mathrm{pH}$ 9.6. Well plates were incubated at $4{ }^{\circ} \mathrm{C}$ for $16 \mathrm{~h}$ under agitation. Then, a $200 \mu \mathrm{l}$ blocking solution (PBS, $2.5 \mathrm{~g} / 1 \mathrm{BSA}$ ) was added for $1 \mathrm{~h}$ and placed at $37{ }^{\circ} \mathrm{C}$. Following three washes with PBS, plates were filled with $100 \mu \mathrm{l}$ of sera diluted at 1:1000 in the blocking buffer A (PBS, $2 \mathrm{~g} / 1 \mathrm{BSA}$ ) and incubated at $37{ }^{\circ} \mathrm{C}$ for $1 \mathrm{~h} \mathrm{45}$. After three washes with PBS- $0.05 \%$ Tween 20 , plates were incubated at $37^{\circ} \mathrm{C}$ for $1 \mathrm{~h}$ with peroxidase-labeled anti-human IgM secondary antibodies diluted respectively at 1: 15,000, in the blocking buffer (PBS, $2 \mathrm{~g} / \mathrm{l} \mathrm{BSA}$ ). They were then washed three times with PBS $0.05 \%$ Tween 20, and incubated with the detection solution for $10 \mathrm{~min}$ in the dark. Chromogen detection solution was used for the peroxidase assay at $8 \%$ in $0.1 \mathrm{M}$ acetate and $0.01 \mathrm{M}$ phosphate buffer (pH 5.0) containing $0.01 \% \mathrm{H}_{2} \mathrm{O}_{2}$. The reaction was stopped with $25 \mu \mathrm{l} 2-\mathrm{N} \mathrm{HCl}$. Optical densities (OD) were measured at $492 \mathrm{~nm}$ using a multiscan spectrophotometer. All assays were carried out in duplicate.

\section{Assays of IgM responses directed against NO adducts}

In order to mimic nitrosylation processes, several conjugates, namely NO-tryptophan (NOW), NO-arginine and NO-cysteinyl, were synthesized by linking haptens to bovine serum albumin (BSA, Sigma-Aldrich) using glutaraldehyde (G) (Boullerne et al. 
1996; Geffard et al. 2003, 2002). The synthesis of these conjugates have been described previously (Boullerne et al. 1995). Each hapten conjugate was nitrosylated using sodium nitrite $\left(\mathrm{NaNO}_{2}\right)$ dissolved in $2 \mathrm{ml}$ of each conjugate, in $0.5 \mathrm{M} \mathrm{HCl}$ at $37^{\circ} \mathrm{C}$ for $2 \mathrm{~h}$, while shaking in the dark. Conjugates were then dialyzed at $4{ }^{\circ} \mathrm{C}$ for $24 \mathrm{~h}$ against a Phosphate Buffered Saline (PBS: $10^{-2} \mathrm{M} \mathrm{NaH}_{2} \mathrm{PO}_{4}, 12 \mathrm{H}_{2} \mathrm{O} ; 0.15 \mathrm{M} \mathrm{NaCl}$; $\mathrm{pH}$ 7.4) solution. S-nitrosothiol bond formation was determined by spectrophotometry. The S-nitrosothiol compounds possess two absorbance maxima, at 336 and $550 \mathrm{~nm}$, respectively: $\mathrm{e}_{336}$ $\mathrm{nm}=900 \mathrm{M}^{-1} \mathrm{~cm}^{-1}$ for the conjugates, $\mathrm{e}_{550} \mathrm{~nm}=4000 \mathrm{M}^{-1} \mathrm{~cm}^{-1}$ for BSA. Absorbance was evaluated in order to determine NO concentrations linked to the compounds.

The assays for the titers of IgM have been extensively described elsewhere (Boullerne et al. 2002; Geffard et al. 2002). Briefly, polystyrene 96 -well plates (NUNC) were coated with $200 \mu \mathrm{l}$ solution containing the conjugates at $10 \mu \mathrm{g} / \mathrm{ml}$ in $0.05 \mathrm{M}$ carbonate buffer at $\mathrm{pH} 9.6$. Well plates were incubated at $4{ }^{\circ} \mathrm{C}$ for $16 \mathrm{~h}$ under agitation. Then, a $200 \mu \mathrm{l}$ of blocking solution (PBS, $2.5 \mathrm{~g} / 1 \mathrm{BSA}$ ) was added for $1 \mathrm{~h}$ and placed at $37{ }^{\circ} \mathrm{C}$. Following three washes with PBS, plates were filled up with $100 \mu \mathrm{l}$ of sera diluted at 1:1000 in the blocking buffer A (PBS, 0.05\% Tween 20, 10\% Glycerol, $2.5 \mathrm{~g} / 1 \mathrm{BSA}, 1 \mathrm{~g} / \mathrm{l} \mathrm{BSA}-\mathrm{G})$ and incubated at $37^{\circ} \mathrm{C}$ for $2 \mathrm{~h}$. After three washes with PBS-0.05\% Tween 20, plates were incubated at $37^{\circ} \mathrm{C}$ for $1 \mathrm{~h}$ with peroxidase-labeled anti-human IgM secondary antibodies diluted respectively at $1: 15,000$, in the blocking buffer (PBS, 0.05\% Tween 20, $2.5 \mathrm{~g} / 1 \mathrm{BSA}$ ). They were then washed three times with PBS- $0.05 \%$ Tween 20 , and incubated with the detection solution for $10 \mathrm{~min}$ in the dark. Chromogen detection solution was used for the peroxidase assay at $8 \%$ in $0.1 \mathrm{M}$ acetate and $0.01 \mathrm{M}$ phosphate buffer (pH 5.0) containing $0.01 \% \mathrm{H}_{2} \mathrm{O}_{2}$. The reaction was stopped with $25 \mu \mathrm{l} 2-\mathrm{N} \mathrm{HCl}$. Optical densities (OD) were measured at $492 \mathrm{~nm}$ using a multiscan spectrophotometer. All assays were carried out in duplicate. The intra-assay CV values were $<6 \%$.

\section{CRP and TRYCAT pathway assays}

hs-CRP was measured using the high sensitivity CRP Vario assay (Abbott Laboratories, Abbott Park, Illinois) on Architect cSystems. Intra-assay CV values were $<4.0 \%$. The synthesis of TRYCAT conjugates was performed as explained previously (Duleu et al. 2010; Kanchanatawan et al. 2017). The 6 TRYCATs were dissolved in $200 \mu \mathrm{L}$ dimethylsulfoxide (DMSO) (Acros). Bovine serum albumin (BSA) (ID Bio) was dissolved in $3 \mathrm{~mL}$ 2-morpholino-ethanesulfonic acid monohydrate (MES Acros) buffer $10^{-1} \mathrm{M}$ at $\mathrm{pH}=6.3$ (Acros). The TRYCATs were then mixed with the BSA solution and supplemented with $15 \mathrm{mg}$ N-hydroxysuccinimide (Sigma) and 1-(3-dimethylaminopropyl)-3-ethylcarbodiimide (Acros) as coupling agents. The conjugates were synthesized by linking 3-
OH-kynurenine (3HK) (Sigma), kynurenic acid (KA) (Acros), quinolinic acid (QA) (Acros), anthranilic acid (AA) (Acros), xanthurenic acid (XA) (Acros) and picolinic acid (PA) (Acros) to $20 \mathrm{mg}$ BSA. The coupling reaction proceeded at $37^{\circ} \mathrm{C}$ for $1 \mathrm{~h}$ in the dark. The coupling was stopped by adding $100 \mathrm{mg}$ hydroxylamine (Sigma-Aldrich) per conjugate. Protein conjugates were dialyzed with $10^{-1} \mathrm{M} \mathrm{NaCl}$ solution, $\mathrm{pH}=6$ for $72 \mathrm{~h}$ and the bath solution was changed at least four times per day. The conjugated TRYCATs and BSA concentrations were evaluated by spectrophotometry. The coupling ratio of each conjugate was determined by measuring the concentration of TRYCATs and BSA at $310-330 \mathrm{~nm}$ and $280 \mathrm{~nm}$, respectively. ELISA tests were used to determine plasma titers of serum immunoglobulin (Ig) M and IgA. Towards this end, polystyrene 96-well plates (NUNC) were coated with $200 \mu \mathrm{L}$ solution containing 10 $50 \mu \mathrm{g} / \mathrm{mL}$ TRYCAT conjugates in $0.05 \mathrm{M}$ carbonate buffer $(\mathrm{pH}=9.6)$. Well plates were incubated under agitation at $4{ }^{\circ} \mathrm{C}$ for $16 \mathrm{~h}$. Then, $200 \mu \mathrm{L}$ blocking buffer A (Phosphate Buffered Saline, PBS, $2.5 \mathrm{~g} / \mathrm{L} \mathrm{BSA}, \mathrm{pH}=7$ ) was applied and all samples were incubated at $37^{\circ} \mathrm{C}$ for $1 \mathrm{~h}$. Well plates were washed with PBS solution and filled up with $100 \mu \mathrm{L}$ serum diluted 1:130 in blocking buffer and incubated at $37^{\circ} \mathrm{C}$ for $1 \mathrm{~h}$ and $45 \mathrm{~min}$. Well plates were washed 3 times with PBS, $0.05 \%$ Tween 20, incubated with peroxidase-labeled goat anti-human IgA (SouthernBiotech) antibodies at $37^{\circ} \mathrm{C}$ for $1 \mathrm{~h}$. The goat antihuman IgM antibody was diluted at 1:5.000 and the IgA antibody was diluted at 1:10,000 in blocking buffer (PBS, $2.5 \mathrm{~g} / \mathrm{L}$ BSA). Plates were then washed three times with PBS, $0.05 \%$ Tween 20. Fifty $\mu \mathrm{L}$ of $3,3^{\prime}, 5,5^{\prime}$-Tetramethylbenzidine (TMB) substrate (SouthernBiotech) was added and incubated for $10 \mathrm{~min}$ in the dark. The reaction was stopped using $50: 1$ of TMB stop solution (SouthernBiotech). Optical densities (ODs) were measured at $450 \mathrm{~nm}$ using Varioskan Flash (Thermo Scientific). All assays were carried out in duplicate. The analytical intra-assays $\mathrm{CV}$ values were $<7 \%$. The $\mathrm{OD}$ scores were expressed as z scores.

\section{Measurements of IgA/IgM responses to gram-negative bacteria}

Antigens derived from the six commensal bacteria were assayed after sonication, namely $C$. koseri, $H$. alvei, $K$. pneumoniae, $M$. morganii, $P$. aeruginosa, and $P$. putida. Protein concentration was assayed by the Bradford method. Briefly, polystyrene 96well plates (NUNC) were coated with $200 \mu$ solution containing bacterial components at $4 \mu \mathrm{g} / \mathrm{ml}$ in $0.05 \mathrm{M}$ carbonate buffer at $\mathrm{pH}$ 9.6. Well plates were incubated at $4{ }^{\circ} \mathrm{C}$ for $16 \mathrm{~h}$ under agitation. Then, we added $200 \mu$ l blocking solution (PBS, Tween 20 $0.05 \%, 5 \mathrm{~g} / 1 \mathrm{BSA}$ ) for $1 \mathrm{~h}$ and placed at $37^{\circ} \mathrm{C}$. Following two washes with PBS, plates were filled up with $100 \mu$ of sera diluted at 1:1000 in the blocking buffer A (PBS, $0.05 \%$ Tween $20,2.5 \mathrm{~g} / \mathrm{BSA}$ ) and incubated at $37^{\circ} \mathrm{C}$ for $105 \mathrm{~min}$. After three washes with PBS- $0.05 \%$ Tween 20 , plates were incubated at 
$37^{\circ} \mathrm{C}$ for $1 \mathrm{~h}$ with peroxidase-labeled anti-human $\operatorname{IgM}$ or $\operatorname{IgA}$ secondary antibodies diluted respectively at 1: 15,000 and 1: 10,000 in the blocking buffer (PBS, 0.05\% Tween 20, $2.5 \mathrm{~g} / 1$ BSA). Afterwards, plates were washed three times with PBS$0.05 \%$ Tween 20 , and incubated with the detection solution for $10 \mathrm{~min}$ in the dark. Chromogen detection solution (Tetramethylbenzedine) was used for the peroxidase assay at $16.6 \mathrm{ml}$ per liter in $0.11 \mathrm{M}$ sodium acetate trihydrate buffer ( $\mathrm{pH}$ 5.5) containing $0.01 \% \mathrm{H}_{2} \mathrm{O}_{2}$. The reaction was stopped with $25 \mu \mathrm{l} 2-\mathrm{N} \mathrm{HCl}$. After addition of stop solution $\left(\mathrm{H}_{2} \mathrm{SO}_{4}\right.$ or $\left.\mathrm{HCl}\right)$, the obtained, proportional absorbance in the tested sample (compared to established concentration of respective antibodies), was measured at $450 \mathrm{~nm}$ with one alpha of correction at $660 \mathrm{~nm}$.

\section{Statistical analysis}

We employed analyses of contingency tables ( $\mathrm{X}^{2}$-test) to assess associations between sets of categorical variables and analyses of variance (ANOVAs) to check differences in continuous variables among treatment means. To check post-hoc differences between group means we used protected least significant difference (LSD). Pearson's product moment correlation analyses were employed to assess the univariate correlations between two continuous variables. We used multivariate general linear model (GLM) analyses to assess the multivariate effects of primary explanatory variables on a set of dependent variables. For example, we used the IgM responses to OSEs or NO-adducts as dependent variables and diagnosis as primary explanatory variable while adjusting for background variables, such as age. We also used the $\operatorname{IgM}$ responses to OSEs or NO-adducts as dependent variables and $\operatorname{IgA} / \operatorname{IgM}$ responses to Gram-negative bacteria as primary explanatory variables while adjusting for pregnancy, age, etc. Finally, we used the $\operatorname{IgM} / \operatorname{IgA}$ responses to Gram-negative bacteria and IgM responses to OSEs and $\mathrm{NO}$-adducts as explanatory variables while indexes of TRYCAT pathway activation were the dependent variables. Consequently, tests for between-subjects effects were employed to examine the effects of the significant explanatory variables on each of the dependent variables. Ln transformations were employed to normalize the data distribution of measures, such as CRP and IgA responses to TRYCATs. All OD values (OSEs, NO-adducts, Gramnegative bacteria, TRYCATS) were transformed into $\mathrm{z}$ scores and $\mathrm{z}$ unit weighted composite scores were used as pathway indices. Total IgM responses to OSEs (IgM OSEs) or NO adducts (IgM OSE adducts) were computed as the sum of all z scores of all separate OSE or NO measurements, respectively. Total IgM (IgM LPS) or IgA (IgA LPS) responsivity to Gram-negative bacteria (an index of total bacterial load) was assessed as sum of all $\mathrm{z}$ scores of $\operatorname{IgA}$ or $\mathrm{IgM}$ responses to the 6 bacterial antigens. The activity of the TRYCAT pathway was assessed as: sum of the $\mathrm{z}$ scores of IgM (IgM TRYCATs) or IgA (IgA TRYCATs) responses to TRYCATs, the $\Delta \operatorname{IgA}-\operatorname{IgM}$ TRYCAT index (that is IgA TRYCAT - IgM TRYCAT) and IgA KYN/TRY (z score IgA against kynurenine $-\mathrm{z}$ score IgA against tryptophan). All statistical analyses were performed using IBM SPSS windows version 22. Tests were 2-tailed and a $p$-value of 0.05 was used for statistical significance.

\section{Results}

\section{Descriptive statistics}

Table 1 shows the demographic and clinical data of nonpregnant women and pregnant women, divided into those with lower versus higher IgM responses directed against OSEs (median split method). There were no significant differences in age between both groups. Education was somewhat lower in pregnant women than in non-pregnant women. End of term EPDS was significantly greater in pregnant than in non-pregnant women. The STAI and post-natal EPDS values were significantly lower in pregnant as compared to nonpregnant women. There was no difference in the incidence of prenatal depression between the two groups of pregnant women when differentiated by high versus low IgM responses to OSEs. There were no significant differences in IgM responses directed to NO-adducts and $\operatorname{IgA}$ responses directed to 6 Gram-negative bacteria or TRYCATs across the three groups. The IgM values directed to OSEs, 6 Gram-negative bacteria or TRYCATs were significantly lower in women belonging to the low IgM group than in the two other groups. The $\Delta$ IgA - IgM TRYCAT values did not differ between the subgroups, while the IgA KYN/TRY ratio was significantly higher in non-pregnant females.

\section{Effects of pregnancy and diagnoses on IgM responses to OSEs and NO-adducts}

Table 2 shows the results of 2 different multivariate GLM analyses with the IgM responses to OSEs or NO-adducts as dependent variables, and diagnosis-pregnancy (3 groups: pregnant with and without prenatal depression and pregnant women), a lifetime diagnosis of depression and alcohol use during pregnancy as primary explanatory variables, while adjusting for effects of age, BMI, etc. In regression \#1 we entered the IgM values against each of the 6 OSE together with IgM OSE as dependent variables. This multivariate GLM analysis revealed significant multivariate effect of diagnosis-pregnancy and use of alcohol. Tests for betweensubjects effects revealed a significant effect of diagnosispregnancy on all IgM responses directed to OSEs, except azelaic acid, and an effect of alcohol use on IgM response to Pi only. Table 3 shows the estimated marginal mean values (SE) of all OSE values obtained after GLM regression and 
Table 1 Demographic data of non-pregnant and pregnant women, divided into those with higher $(>-1.8088 \mathrm{z})$ and lower $(<-1.8088 \mathrm{z})$ OSE (oxidative specific epitopes) values

\begin{tabular}{lllllll}
\hline Variables & Non-pregnant $^{\mathrm{a}}$ & $\begin{array}{l}\text { Pregnant } \\
\text { OSE }>-1.8088^{\mathrm{b}}\end{array}$ & $\begin{array}{l}\text { Pregnant } \\
\text { OSE }<-1.8088^{\mathrm{c}}\end{array}$ & F/X & df & $\mathrm{p}$ \\
\hline Age (years) & $28.1(3.2)$ & $29.3(6.9)$ & $27.7(6.6)$ & 0.53 & $2 / 70$ & 0.593 \\
Year education & $17.7(1.3)^{\mathrm{b}, \mathrm{c}}$ & $11.7(4.6)^{\mathrm{a}}$ & $12.8(2.7)^{\mathrm{a}}$ & 24.69 & $2 / 67$ & $<0.001$ \\
Actual BMI & $20.5(2.7)^{\mathrm{b}, \mathrm{c}}$ & $26.2(5.7)^{\mathrm{a}}$ & $27.1(3.9)^{\mathrm{a}}$ & 16.57 & $2 / 70$ & $<0.001$ \\
EPDS end term & $4.3(3.0)^{\mathrm{b}, \mathrm{c}}$ & $9.4(6.8)^{\mathrm{a}}$ & $8.1(6.5)^{\mathrm{a}}$ & 5.09 & $2 / 69$ & 0.009 \\
STAI end term & $49.6(6.3)^{\mathrm{b}, \mathrm{c}}$ & $43.4(9.3)^{\mathrm{a}}$ & $41.6(11.7)^{\mathrm{a}}$ & 4.88 & $2 / 69$ & 0.010 \\
EPDS T2 postnatal & $4.3(3.0)^{\mathrm{b}, \mathrm{c}}$ & $3.4(5.1)$ & $2.5(3.1)$ & 1.22 & $2 / 62$ & 0.300 \\
STAI T2 postnatal & $49.6(6.3)^{\mathrm{b}, \mathrm{c}}$ & $35.0(8.2)^{\mathrm{a}}$ & $33.2(6.3)^{\mathrm{a}}$ & 38.27 & $2 / 61$ & $<0.001$ \\
Prenatal MDD (N/Y) & $24 / 0$ & $12 / 13$ & $13 / 11$ & $\mathrm{NA}$ & - & - \\
IgM OSE (z score) & $3.05(5.69)^{\mathrm{c}}$ & $1.45(2.96)^{\mathrm{c}}$ & $-4.55(2.19)^{\mathrm{a}, \mathrm{b}}$ & 25.35 & $2 / 70$ & $<0.001$ \\
IgM NO (z-score) & $-0.39(1.59)$ & $0.40(1.65)^{\mathrm{c}}$ & $-0.03(2.46)$ & 1.01 & $2 / 70$ & 0.369 \\
IgA LPS (z-score) & $2.60(4.93)^{\mathrm{c}}$ & $0.11(3.64)^{\mathrm{c}}$ & $-2.72(4.77)^{\mathrm{a}, \mathrm{b}}$ & 8.49 & $2 / 70$ & 0.001 \\
IgM LPS (z-score) & $0.21(1.11)^{\mathrm{c}}$ & $0.39(0.94)^{\mathrm{c}}$ & $-0.61(0.60)^{\mathrm{a}, \mathrm{b}}$ & 8.30 & $2 / 70$ & 0.001 \\
IgA TRYCATs (z-score) & $1.52(8.4)$ & $-0.43(0.84)$ & $-1.08(8.37)$ & 0.71 & $2 / 70$ & 0.497 \\
IgM TRYCATs (z score) & $1.80(6.61)^{\mathrm{c}}$ & $2.70(5.87)^{\mathrm{c}}$ & $-4.62(5.28)^{\mathrm{a}, \mathrm{b}}$ & 10.94 & $2 / 70$ & $<0.001$ \\
IIgA - IgM TRYCATs & $-0.28(10.75)$ & $-3.13(8.15)$ & $3.54(9.58)$ & 3.01 & $2 / 70$ & 0.056 \\
$\quad$ (z score) & & & & & & \\
IgA KYN/TRY (z score) & $0.50(0.82)^{\mathrm{b}, \mathrm{c}}$ & $-0.39(1.32)^{\mathrm{a}}$ & $-0.10(0.66)^{\mathrm{a}}$ & 7.08 & $2 / 70$ & 0.002 \\
hs CRP (mg/dL) & $1.57(2.04)^{\mathrm{b}, \mathrm{c}}$ & $5.76(5.49)^{\mathrm{a}}$ & $4.39(4.03)^{\mathrm{a}}$ & 16.92 & $2 / 69$ & $<0.001$ \\
\hline
\end{tabular}

All data are shown as mean $( \pm \mathrm{SD})$

$B M I$ body mass index, EPDS Edinburgh Postnatal Depression Scale, STAI Spielberger's State Anxiety Inventory, PC PS: first principal component subtracted from the physio-somatic symptoms, IgM OSE sum of z-scores of the IgM responses to all OSE measurements, IgM NO sum of z-scores of the IgM responses to all NO-adduct measurements, IgM LPS sum of z-scores of the IgM responses directed against 6 g-negative bacteria, IgA LPS sum of $\mathrm{z}$-scores of the IgA responses directed against $6 \mathrm{~g}$-negative bacteria, IgM TRYCATs sum of z-scores of the IgM responses directed against tryptophan catabolites, IgA TRYCATs sum of z-scores of the IgA responses directed against tryptophan catabolites, $\triangle \operatorname{IgA}$-IgM TRYCATS sum of z scores of all IgA responses to TRYCATs - sum of z scores of all IgM responses to TRYCATs, IgA KYN/TRY z score IgA directed against kynurenine - z score IgA directed against tryptophan

${ }^{\mathrm{a}, \mathrm{b}, \mathrm{c}}$ Denotes pairwise differences between the three categories protected post-hoc analyses on the group mean values. All IgM values were significantly lower in pregnant women as compared to nonpregnant women, while there was no significant effect of prenatal depression. The use of alcohol significantly increased IgM responses to Pi. In regression \#2 we entered the IgM responses directed to $3 \mathrm{NO}$-adduct values and IgM NO adducts as dependent variables but we could not find any significant effect of diagnosis-pregnancy, while there were significant multivariate effects of alcohol use and a lifetime diagnosis of depression. Tests for between-subject effects and Table 3 show that alcohol use lowers the IgM responses to NO-tryptophan (NOW), while a lifetime history of depression was accompanied by significantly increased IgM responses to NO-cysteinyl and IgM NO adducts.
Table 2 Results of multivariate GLM analysis with the IgM responses directed against oxidative specific epitopes (OSEs) and 3 nitric oxide (NO) adducts as dependent variables

\begin{tabular}{llllll}
\hline Tests & Dependent variables & Exploratory variables & F & df & p \\
\hline Multivariate \#1 & All 6 OSEs & Diagnosis-pregnancy & 4.17 & $12 / 124$ & $<0.001$ \\
& & Alcohol & 3.43 & $6 / 62$ & 0.006 \\
& & MDD-Life & 0.77 & $6 / 62$ & 0.589 \\
Between-subject effects & Age & 1.54 & $6 / 62$ & 0.180 \\
& IgM MDA & Diagnosis-pregnancy & 11.14 & $1 / 67$ & $<0.001$ \\
& IgM Pi & Diagnosis-pregnancy & 8.11 & $1 / 67$ & 0.001 \\
& & Alcohol & 5.03 & $1 / 67$ & 0.028 \\
& IgM Palmitic acid & Diagnosis-pregnancy & 6.37 & $1 / 67$ & 0.003 \\
& IgM Myristic acid & Diagnosis-pregnancy & 9.25 & $1 / 67$ & $<0.001$ \\
& IgM Farnesyl cysteine & Diagnosis-pregnancy & 4.23 & $1 / 67$ & 0.019 \\
& IgM total & Diagnosis-pregnancy & 8.84 & $1 / 67$ & $<0.001$ \\
Multivariate \#2 & IgM 3 NO adducts & Diagnosis-pregnancy & 1.59 & $6 / 130$ & 0.155 \\
& & Alcohol & 2.88 & $3 / 65$ & 0.043 \\
& & MDD-Life & 3.31 & $3 / 65$ & 0.025 \\
& & Age & 1.97 & $3 / 65$ & 0.128 \\
Between - subject effects & Alcohol & 7.25 & $1 / 67$ & 0.009 \\
& IgM NOW & MDD-Life & 8.27 & $1 / 67$ & 0.003 \\
& IgM NO-Cysteinyl & MDD-Life & 4.13 & $1 / 67$ & 0.046
\end{tabular}

MDD-Life lifetime diagnosis of major depression, Alcohol alcohol consumption during pregnancy, MDA malondialdehyde, $P i$ phosphatidylinositol, NOW NO-tryptophan 
Table 3 Estimated marginal means (SE; in z-values) of IgM response to oxidative specific epitopes (OSEs) and NO-adducts obtained by multivariate regression listed in Table 2

\begin{tabular}{llll}
\hline Variables & Not pregnant & Pregnant & $\begin{array}{c}\text { Pregnant }+ \text { antenatal } \\
\text { depression }\end{array}$ \\
\hline IgM MDA & $0.99(0.25)^{\mathrm{b}, \mathrm{c}}$ & $-0.05(0.24)^{\mathrm{a}}$ & $-0.17(0.19)^{\mathrm{b}}$ \\
IgM Azelaic acid & $0.50(0.27)$ & $-0.02(0.26)$ & $0.22(0.21)$ \\
IgM Pi & $0.80(0.26)^{\mathrm{b}, \mathrm{c}}$ & $-0.22(0.25)^{\mathrm{a}}$ & $-0.05(0.20)^{\mathrm{a}}$ \\
IgM Palmitic acid & $0.67(0.27)^{\mathrm{b}, \mathrm{c}}$ & $-0.21(0.25)^{\mathrm{a}}$ & $-0.21(0.20)^{\mathrm{a}}$ \\
IgM Myristic acid & $0.83(0.26)^{\mathrm{b}, \mathrm{c}}$ & $-0.24(0.25)^{\mathrm{a}}$ & $-0.14(0.20)^{\mathrm{a}}$ \\
IgM Farnesyl Cysteine & $0.55(0.27)^{\mathrm{b}, \mathrm{c}}$ & $-0.16(0.26)^{\mathrm{a}}$ & $-0.22(0.21)^{\mathrm{a}}$ \\
IgM Total OSE & $4.34(1.31)^{\mathrm{b}, \mathrm{c}}$ & $-0.90(1.25)^{\mathrm{a}}$ & $-0.57(1.00)^{\mathrm{a}}$ \\
IgM NO-Arginine & $-0.34(0.28)$ & $0.39(0.26)$ & $-0.19(0.21)$ \\
IgM NOW & $-0.36(0.27)$ & $0.08(0.26)$ & $-0.37(0.21)$ \\
IgM NO-Cysteinyl & $0.36(0.27)$ & $0.52(0.26)$ & $0.22(0.21)$ \\
IgM Total NO & $-0.35(0.52)$ & $0.98(0.50)$ & $-0.34(0.40)$ \\
Variables & No Alcohol & Alcohol & \\
IgM Pi & $-0.15(0.16)$ & $0.05(0.27)$ & \\
IgM NOW & $0.20(0.17)$ & $-0.63(0.29)$ & \\
Variables & No MDD-Life & MDD-Life & \\
IgM NO-Cysteinyl & $-0.12(0.16)$ & $0.85(0.31)$ & \\
IgM Total NO & $-0.56(0.31)$ & $0.75(0.59)$ & \\
\hline
\end{tabular}

MDA malondialdehyde, Pi phosphatidylinositol, NOW NO-tryptophan, Alcohol consumption during pregnancy, $M D D$-Life lifetime diagnosis of major depression

${ }^{\mathrm{a}, \mathrm{b}, \mathrm{c}}$ Denotes pairwise differences between the three categories

\section{Associations between commensal bacteria and IgM responses to OSEs}

Using correlation analyses we detected significant correlations between IgA LPS and IgM OSEs $(r=0.375, p=0.001), \operatorname{IgM}$ responses to MDA ( $r=0.401, p=0.001)$, IgM responses to azelaic acid $(r=0.233, p=0.047)$, IgM responses to $\mathrm{Pi}$ $(r=0.472, p<0.001)$, IgM responses to palmitic acid $(r=0.279, p=0.017)$, and IgM responses to myristic acid $(r=0.376, p=0.001)$. There were also highly significant correlations between IgM LPS and IgM OSEs $(r=0.760$, $p<0.001)$ and with all separate OSEs $(r>0.560$, $p<0.001)$. Table 4 shows the outcomes of multivariate GLM analysis \#1 and \#2 with all IgM responses to OSEs as dependent variables and IgA and IgM LPS as explanatory variables. We found highly significant multivariate effects of IgA and IgM LPS on all OSEs variables. Tests for betweensubject effects revealed that all IgM responses to OSEs were positively associated with IgA LPS and IgM LPS. In order to delineate which bacteria are most important we have carried out additional analyses will all 6 Gram-negative bacteria as dependent variables (IgM or IgA). Multivariate GLM analysis \#3 shows a multivariate effect of the IgA responses to Morganella on the IgM OSE values, while univariate analysis showed an effect on IgM responses to Pi and myristic acid. Multivariate GLM analysis \#4 shows a multivariate effect of the IgM responses to $K$. pneumoniae and $C$. koseri. Univariate analyses showed that IgM responses to K. pneumoniae were associated with IgM responses to azelaic acid, Pi and all OSEs together, while $C$. koseri was significantly associated with IgM responses to all OSEs.

\section{Associations between commensal bacteria and IgM responses to $\mathrm{NO}$-adducts}

Using correlation analyses, we detected significant correlations between IgA LPS and IgM responses to NOW $(r=-0.307, p=0.008)$ but not the other NO-adducts. Correlation analyses showed significant correlations between IgM LPS and IgM responses to NO cysteinyl $(r=-0.413$, $p<0.001$ ). Table 5, multivariate GLM analysis \#1 shows no significant multivariate association between IgA LPS and IgM NO-adducts, while regression \#2 shows that there was a significant multivariate association between IgM LPS and IgM responses to NO-adducts. Univariate analysis showed a significant association with IgM responses to NO-cysteinyl only.

Multivariate analysis \#3 shows that IgA responses to C. koseri had a significant multivariate effect on the IgM against NO-adducts while univariate effects shows a significant effect on IgM NO-cysteinyl only. Multivariate analysis \#4 shows that IgM responses to $C$. koseri had a significant multivariate effect, while tests for between-subjects effects showed an effect of IgM responses to C. koseri on NO-cysteinyl only.

\section{Associations between the TRYCAT pathway and IgM responses to OSEs and NO-adducts}

In order to examine the associations between $\operatorname{IgM} / \operatorname{IgA}$ against TRYCATs, on the one hand, and IgM/IgA LPS, IgM OSEs and IgM NO-adducts, CRP and a lifetime history of PMS and depression, on the other, we performed a multivariate GLM analysis with the TRYCATs as dependent variables (entered as IgM TRYCATs, IgA TRYCATs, $\triangle \mathrm{IgA}$ - IgM TRYCATs, and IgA 
Table 4 Results of multivariate GLM analysis with IgM response directed against oxidative specific epitopes (OSEs) as dependent variables

\begin{tabular}{|c|c|c|c|c|c|}
\hline Test & Dependent variables & Independent variables & $\mathrm{F}$ & $\mathrm{df}$ & $\mathrm{p}$ \\
\hline Multivariate \#1 & IgM all OSEs & IgA LPS & 5.37 & $6 / 66$ & $<0.001$ \\
\hline \multirow[t]{7}{*}{ Between- subject effects } & IgM MDA & IgA LPS & 10.12 & $1 / 71$ & 0.002 \\
\hline & IgM Azelaic acid & IgA LPS & 4.71 & $1 / 71$ & 0.033 \\
\hline & IgM Pi & IgA LPS & 16.13 & $1 / 71$ & $<0.001$ \\
\hline & IgM Palmitic acid & IgA LPS & 7.03 & $1 / 71$ & 0.010 \\
\hline & IgM Myristic acid & IgA LPS & 14.81 & $1 / 71$ & $<0.001$ \\
\hline & IgM Farnesyl-Cysteine & IgA LPS & 5.20 & $1 / 71$ & 0.026 \\
\hline & IgM Total OSEs & IgA LPS & 13.31 & $1 / 71$ & 0.001 \\
\hline \multirow{2}{*}{ Multivariate \#2 } & IgM All OSEs & IgM LPS & 25.23 & $6 / 65$ & $<0.001$ \\
\hline & & Pregnancy & 8.59 & $6 / 65$ & $<0.001$ \\
\hline \multirow[t]{7}{*}{ Between- subject effects } & IgM MDA & IgM LPS & 33.23 & $1 / 70$ & $<0.001$ \\
\hline & IgM Azelaic acid & IgM LPS & 49.73 & $1 / 70$ & $<0.001$ \\
\hline & IgM Pi & IgM LPS & 130.26 & $1 / 70$ & $<0.001$ \\
\hline & IgM Palmitic acid & IgM LPS & 33.29 & $1 / 70$ & $<0.001$ \\
\hline & IgM Myristic acid & IgM LPS & 65.76 & $1 / 70$ & $<0.001$ \\
\hline & IgM Farnesyl-Cysteine & IgM LPS & 43.50 & $1 / 70$ & $<0.001$ \\
\hline & IgM Total OSEs & IgM LPS & 16.64 & $1 / 70$ & $<0.001$ \\
\hline Multivariate \#3 & IgM All OSEs & IgA Morganella morganii & 4.48 & $6 / 64$ & 0.001 \\
\hline \multirow[t]{2}{*}{ Between-subject effects } & IgM Pi & IgA $M$. morganii & 7.96 & $1 / 71$ & 0.006 \\
\hline & IgM Myristic Acid & IgA $M$. morganii & 7.81 & $1 / 71$ & 0.007 \\
\hline \multirow[t]{2}{*}{ Multivariate \#4 } & IgM all OSEs & IgM Klebsiella pneumoniae & 3.83 & $6 / 65$ & 0.002 \\
\hline & & IgM Citrobacter koseri & 5.51 & $6 / 65$ & $<0.001$ \\
\hline \multirow[t]{3}{*}{ Between- subject effects } & IgM Azelaic acid & IgM K. pneumoniae & 11.97 & $1 / 70$ & 0.001 \\
\hline & IgM Pi & IgM K. pneumoniae & 16.53 & $1 / 70$ & $<0.001$ \\
\hline & IgM Total OSEs & IgM K. pneumoniae & 6.23 & $1 / 70$ & 0.015 \\
\hline \multirow[t]{7}{*}{ Between- subject effects } & IgM MDA & IgM C. koseri & 10.25 & $1 / 70$ & 0.006 \\
\hline & IgM Azelaic acid & IgM C. koseri & 5.77 & $1 / 70$ & 0.008 \\
\hline & IgM Pi & IgM C. koseri & 26.86 & $1 / 70$ & $<0.001$ \\
\hline & IgM Palmitic acid & IgM C. koseri & 13.65 & $1 / 70$ & $<0.001$ \\
\hline & IgM Myristic acid & IgM C. koseri & 25.51 & $1 / 70$ & $<0.001$ \\
\hline & IgM Farnesyl-cysteine & IgM C. koseri & 15.77 & $1 / 70$ & $<0.001$ \\
\hline & IgM Total OSEs & IgM C. koseri & 28.15 & $1 / 70$ & $<0.001$ \\
\hline
\end{tabular}

MDA malondialdehyde, $P i$ phosphatidylinositol, NOW NO-tryptophan
KYN/TRY). Table 6 shows the outcome of this multivariate analysis. We found significant effects of a lifetime history of PMS and major depression, IgM OSEs and IgM NO-adducts, IgA LPS (but not IgM LPS) and CRP. Tests for between-subject effects showed that IgA TRYCATs was strongly associated with IgA LPS and PMS (both positively) and CRP (inversely). IgM TRYCATs were positively associated with IgM OSEs. The $\triangle$ IgA - IgM TRYCAT values were significantly predicted by
Table 5 Results of multivariate GLM analysis with IgM response directed against nitric oxide (NO) adducts as dependent variables

\begin{tabular}{llllll}
\hline Tests & Dependent variables & Independent variables & F & df & p \\
\hline Multivariate \#1 & IgM all NO adducts & IgA LPS & 2.40 & $3 / 67$ & 0.076 \\
& & MDD-Life & 2.73 & $3 / 67$ & 0.051 \\
& & Alcohol & 2.49 & $3 / 67$ & 0.068 \\
Multivariate \#2 & IgM all NO adducts & IgM LPS & 5.33 & $3 / 67$ & 0.002 \\
& & MDD-Life & 3.42 & $3 / 67$ & 0.022 \\
& & Alcohol & 1.81 & $3 / 67$ & 0.155 \\
Between- subject effects & IgM NO Arginine & IgM LPS & 1.51 & $1 / 69$ & 0.223 \\
& IgM NOW & IgM LPS & 1.87 & $1 / 69$ & 0.176 \\
& IgM NO-Cysteine & IgM LPS & 15.32 & $1 / 69$ & $<0.001$ \\
& IgM Total NO & IgM LPS & 0.20 & $1 / 69$ & 0.659 \\
Multivariate \#3 & IgM all NO adducts & IgA Citrobacter koseri & 3.82 & $3 / 67$ & 0.014 \\
& & MDD-Life & 2.74 & $3 / 67$ & 0.050 \\
Between- subject effects & Alcohol & 2.08 & $3 / 67$ & 0.111 \\
Multivariate \#4 & IgM NO-Cysteinyl & IgA C. koseri & 8.72 & $1 / 69$ & 0.004 \\
& IgM all NO adducts & IgM C. koseri & 7.22 & $1 / 69$ & $<0.001$ \\
& & MDD-Life & 2.56 & $3 / 67$ & 0.062 \\
Between- subject effects & IgM NO-Cysteinyl & Alcohol & 1.77 & $3 / 67$ & 0.162 \\
& & IgM C. koseri & 20.50 & $1 / 69$ & $<0.001$ \\
\hline
\end{tabular}

MDA malondialdehyde, Pi phosphatidylinositol, NOW NO-tryptophan, Alcohol consumption during pregnancy, $M D D$-Life lifetime diagnosis of major depression 
Table 6 Results of multivariate GLM analysis with the tryptophan catabolite (TRYCAT) data as dependent variables

\begin{tabular}{|c|c|c|c|c|c|}
\hline Tests & Dependent variables & $\begin{array}{l}\text { Exploratory } \\
\text { variables }\end{array}$ & F & df & $\mathrm{p}$ \\
\hline \multirow[t]{6}{*}{ Multivariate } & \multirow{6}{*}{$\begin{array}{l}\Delta \text { IgA-IgM TRYCATs, } \\
\text { IgA TRYCATs, } \\
\text { IgM TRYCATs, and IgA } \\
\text { KYN/TRY }\end{array}$} & PMS lifetime & 4.16 & $3 / 63$ & 0.009 \\
\hline & & MDD Lifetime & 2.95 & $3 / 63$ & 0.039 \\
\hline & & IgM OSEs & 29.66 & $3 / 63$ & $<0.001$ \\
\hline & & IgM NO-adducts & 4.13 & $3 / 63$ & 0.010 \\
\hline & & IgA LPS & 8.52 & $3 / 63$ & $<0.001$ \\
\hline & & CRP & 5.23 & $3 / 63$ & 0.003 \\
\hline \multirow{10}{*}{$\begin{array}{l}\text { Between- subject } \\
\text { effects }\end{array}$} & \multirow[t]{3}{*}{ IgA All TRYCATs } & PMS lifetime (+) & 9.45 & $1 / 65$ & 0.003 \\
\hline & & $\operatorname{IgA} \operatorname{LPS}(+)$ & 24.53 & $1 / 65$ & $<0.001$ \\
\hline & & CRP $(-)$ & 4.54 & $1 / 65$ & 0.037 \\
\hline & IgM All TRYCATs & IgM Total OSEs (+) & 88.66 & $1 / 65$ & $<0.001$ \\
\hline & \multirow[t]{3}{*}{$\Delta$ IgA-IgM TRYCATs } & $\operatorname{IgA} \operatorname{LPS}(+)$ & 22.87 & $1 / 65$ & $<0.001$ \\
\hline & & IgM OSEs (-) & 44.05 & $1 / 65$ & $<0.001$ \\
\hline & & $\mathrm{CRP}(-)$ & 4.54 & $1 / 65$ & 0.037 \\
\hline & \multirow[t]{3}{*}{ IgA KYN/TRY } & MDD lifetime (+) & 7.75 & $1 / 65$ & 0.007 \\
\hline & & $\operatorname{IgM} \mathrm{NO}(-)$ & 12.21 & $1 / 65$ & 0.001 \\
\hline & & CRP $(-)$ & 14.07 & $1 / 65$ & $<0.001$ \\
\hline
\end{tabular}

PMS lifetime lifetime history of pre-menstrual syndrome, MDD lifetime lifetime history of major depression, IgM TRYCATs sum of z-scores of the IgM responses directed against tryptophan catabolites, IgA: TRYCATs sum of zscores of the IgA responses directed against tryptophan catabolites, $\triangle \operatorname{IgA} I \operatorname{Ig} M T R Y C A T s$ sum of z scores of all IgA responses to TRYCATs - sum of z scores of all IgM responses to TRYCATs, IgA KYN/TRY z score IgA directed against kynurenine - z score IgA directed against tryptophan, IgMOSE sum of z-scores of the IgM responses to all OSE measurements, IgMNO sum of z-scores of the IgM responses to all NO-adduct measurements, IgA LPS sum of z-scores of the IgA responses directed against $6 \mathrm{~g}$-negative bacteria, $C R P \mathrm{C}$-reactive protein
IgA LPS (positively) and were negatively correlated with CRP and IgM OSEs. The IgA KYN/TRY ratio was predicted by IgM NO-adducts, CRP and a lifetime history of depression.

\section{Best prediction of the TRYCAT pathway biomarkers}

Consequently, we have examined which OSEs, NO-adducts and bacteria were most significant in predicting the TRYCAT variables. This analysis showed effects of IgM responses to MDA ( $\mathrm{F}=6.24, \mathrm{df}=3 / 63, p=0.001)$, myristic acid $(\mathrm{F}=6.60, \mathrm{df}=3 / 63, p=0.001)$, and NO-cysteinyl $(\mathrm{F}=9.35$, $\mathrm{df}=3 / 63, p<0.001)$ and IgA responses to $P$. putida $(\mathrm{F}=4.46$, $\mathrm{df}=3 / 63, p=0.007)$ on the TRYCAT variables. Tests for between-subject effects showed that IgM responses to MDA were associated with IgM TRYCATs $(\mathrm{F}=17.98, \mathrm{df}=1 / 65$, $p<0.001$, positively) and $\Delta \operatorname{IgA}-\operatorname{IgM}$ TRYCATs values ( $\mathrm{F}=9.12, \mathrm{df}=1 / 65, p=0.002$, negatively). Also, the IgM responses to myristic acid were associated with $\operatorname{IgM}$ TRYCATs ( $\mathrm{F}=19.98, \mathrm{df}=1 / 65, p<0.001$, positively) and $\triangle \mathrm{IgA}$ - IgM TRYCATs values $(\mathrm{F}=7.29, \mathrm{df}=1 / 65, p=0.009$, negatively). The IgM responses to NO-cysteinyl predicted the IgA KYN/TRY ratio $(\mathrm{F}=19.74, \mathrm{df}=1 / 65, p<0.001)$, while $\operatorname{IgA}$ responses to $P$. putida were positively related to $\Delta \operatorname{IgA}-\operatorname{IgM}$ TRYCATs values $(\mathrm{F}=4.46, \mathrm{df}=3 / 63, p=0.007)$.

\section{Discussion}

The first major finding of this study is that pregnancy is accompanied by highly significant decreases in IgM responses directed against OSEs, including MDA, Pi and anchorage molecules, such as myristic and palmitoylic acid and farnesyl cysteine. The lowered IgM-mediated autoimmune responses to these molecules expressed on outer and inner membrane may indicate lowered regulatory IgM autoimmune responses, reflective of impaired normal regulatory responses that neutralize cellular debris, such as apoptotic and dying cells expressing MDA and oxidized low-density lipoprotein (LDL), arising from oxidative stress-induced damage (Rahman et al. 2016). Previous data indicates that pregnancy is accompanied by increased levels of advanced oxidation protein products, suggesting increased protein oxidation (Fialová et al. 2003). Thus, the lowered levels of regulatory IgM responses directed to OSEs could contribute to an enhancement of the detrimental consequences of oxidative stress, thereby promoting more inflammation (Frostegård 2013; Rahman et al. 2016). Previously, we have discussed the role of IgM-mediated regulatory responses as part of the compensatory (anti-)inflammatory reflex system (CIRS) in neuro-psychiatric disorders (Kanchanatawan et al. 2017; Maes et al. 2011a, b; Morris and Maes 2013). Moreover, the Th2 cytokine predominance (humoral immunity) in early pregnancy gradually shifts towards a Th1 (cell-mediated immunity) predominance in late gestation (Challis et al. 2009). This together with lowered regulatory IgM-mediated natural autoimmune responses may play a role in the increased incidence of some autoimmune disorders during pregnancy or complicated pregnancies in women who suffer from autoimmune disease (Challis et al. 2009).

While the IgM responses to OSEs are significantly suppressed during pregnancy, the IgM responses to NO-adducts were unaffected. S-nitrosylation is one of the mechanisms 
underlying uterine smooth muscles relaxation effects of NO (Ulrich et al. 2012). In the guinea pig, the same authors detected protein S-nitrosylation, which plays a role in uterine relaxation and contraction, and are increased independently of raised levels of protein expression. In sheep, pregnancy increases total Snitrosylation but decreases S-nitrosylation of the endothelial NO synthesizing system (Zhang et al. 2012).

In the current study, perinatal depression was not associated with IgM responses directed against OSEs and NO-adducts. These results, however, do not preclude that perinatal depression may be accompanied by O\&NS. No previous studies have investigated oxidative stress in perinatal depression. Nevertheless, a hypothesis had been proposed describing a possible relationship between perinatal depression, oxidative stress, and risk for pregnancy-associated cardiovascular diseases (CVD) (Nicholson et al. 2016). An animal study showed an association of lowered maternal care, a possible indicator of maternal emotional problems, and increased oxidative stress in the brain of nursing mothers (Nicholson et al. 2016). It is not unlikely that lowered IgM-mediated regulatory responses during pregnancy may play a role in the increased incidence of cardiovascular complications during pregnancy and in women of childbearing age (Mohamed 2014). Indeed, attenuation of the regulatory autoimmune responses, which neutralize apoptotic cells expressing oxidized LDL and MDA (Rahman et al. 2016), may be associated with increased expression of oxidized LDL in pregnancy (Ghaneei et al. 2015).

Our results show that alcohol abuse affects IgM responses to Pi. This is consistent with a study reporting higher antibodies directed against $\mathrm{Pi}$ in patients with alcoholic liver disease, especially in alcoholic patients with more severe liver damage (Chedid et al. 1994). Moreover, chronic alcohol consumption may enhance reactive oxygen species (ROS) in mitochondria, thereby affecting mitochondrial functions, including raising levels of mitochondrial cytochrome P450 (CYP2E1) (AdamVizi 2005; Albano 2006; Manzo-Avalos and Saavedra-Molina 2010; Ronis et al. 1996), thereby contributing to pathological swelling and mitochondrial dysfunction (Wakabayashi 2002). Interestingly, Pi may be found in the mitochondria outer membrane (Wakabayashi 2002) and, therefore, when exposed to alcohol-induced ROS, the outer membrane of mega mitochondrial complexes may rupture (Manzo-Avalos and Saavedra-Molina 2010; Wakabayashi 2002), leading to increased IgM responses to Pi.

Another major finding of this study is that the natural IgM mediated autoimmune responses directed against OSEs are associated with indices of increased IgA/IgM responses to Gramnegative bacteria, especially $M$. morganii, C. koseri, and $K$. pneumoniae. This may suggest that natural IgM-mediated immune responses to OSEs are driven by increased bacterial translocation of Gram-negative bacteria and that suppressed IgM-mediated immune responses to OSEs in pregnancy are a consequence of lowered bacterial translocation in pregnancy. In general, the gut microbial composition changes drastically from early to late pregnancy and the gut mucosal surface may present low grade inflammation (Koren et al. 2012), while less inflammatory responsivity may be present at the placental interface (Mor and Cardenas 2010). Future research should examine the associations between bacterial translocation, gut-inflammation, O\&NS, IgM-mediated autoimmune responses and placental interface immune system activity.

Another major finding of this study is that IgM responses to nitrosylated proteins (NO-adducts) are strongly associated with a lifetime diagnosis of depression and increased bacterial translocation, as measured with $\operatorname{IgM} / \operatorname{IgA}$ directed to Gram-negative bacteria, especially $C$. koseri. Importantly, major depressive disorder is associated with increased IgM responses directed against SNO-cysteinyl, a potential neurotoxic compound (Maes et al. 2011a, b). This finding is in agreement with previous research showing increased IgM responses to NO-adducts in general and SNO-cysteinyl in depression (Maes et al. 2013a, b). Studies among MS patients found significantly increased IgM-mediated autoimmune responses directed against SNOcysteine, which is proposed to play a role in the demyelination that characterizes MS (Boullerne et al. 1996, 1995). Previously, we have shown that increased bacterial translocation (as assessed by increased levels of IgA directed against Gramnegative bacteria) is associated with increased IgM response to NO-adducts (Maes et al. 2013a, b).

A further major finding of this study is that the activation of the TRYCAT pathway is strongly predicted by the combined effects of lifetime diagnoses of depression and PMS, bacterial translocation (IgA responses to Gram-negative bacteria) (all three positively) and IgM responses to OSEs and NO adducts and CRP (all three negatively associated). This indicates that major depressive disorder and PMS may be accompanied by a chronic activation of the TRYCAT pathway. The findings are also in agreement with the activation of the TRYCAT pathway by LPS directly, or indirectly by LPS-induced Th1 and M1 macrophagic responses (Martinez et al. 2008). The inverse association between TRYCAT pathway activation and IgM responses to OSEs may indicate that the more general regulatory functions exerted by these autoimmune responses also modulate the TRYCAT pathway, for example by lowering inflammatory and oxidative responses and/or by regulating the activity of the pathway.

Likewise the inverse association between TRYCAT pathway activity and IgM responses to NO-adducts may be explained by direct negative regulatory effects of NO on IDO production (Hucke et al. 2004) or by regulatory effects of nitrosylation on inflammatory responses, for example by inhibiting nuclear factor- $\mathrm{kB}$ (Prasad 2007). We found also a negative correlation between TRYCAT pathway activation and CRP, although some previous studies detected a positive correlation between elevated CRP and increased IDO activity in patients with ischemic stroke (Mo et al. 2014). Nevertheless, CRP also displays anti- 


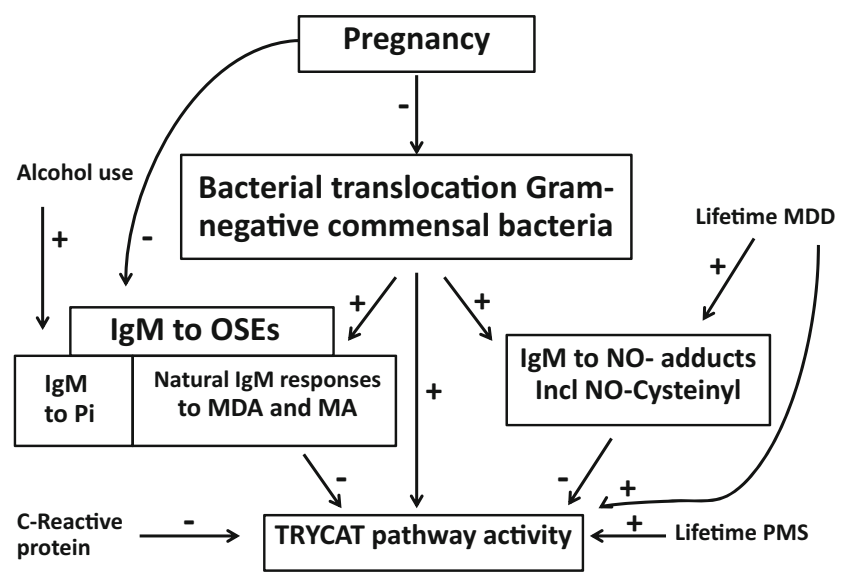

Fig. 1 Summary of our findings

inflammatory effects (Ridker and Lüscher 2014) for example, by preventing neutrophil-endothelial adhesion (Thiele et al. 2014) or decreased production of pro-inflammatory and antiinflammatory cytokines in target areas (Mold and Clos 2013). All in all, it appears that the TRYCAT pathway is regulated in a complex manner by many different processes. It should also be borne in mind that the placenta is a significant source of melatonin for mother and foetus, which has antioxidant and antiinflammatory effects, as well as protecting mitochondria at the consequences of CYP2E1 induction (Liang et al. 2012).

This paper has some limitations and strengths that should be considered when interpreting the results. A limitation is that this study is a case-control study and thus no inferences can be made on causality. It would have been more informative if we had measured alterations in serum IgM responses to OSEs and NOadducts 4-6 weeks after delivery. A first strength is that in this study multivariate GLM analyses were employed and that univariate associations were only interpreted when there were significant overall multivariate effects, thereby reducing type I errors. Secondly, we adjusted for many different background variables and examined the cumulative effects of the predictor variables using multivariate GLM analyses.

Figure 1 summarizes the findings of this study. Natural IgMmediated autoimmune responses directed against OSEs are significantly decreased in pregnancy. It is hypothesized that bacterial translocation may drive the IgM-mediated immune responses and that since bacterial translocation is lowered during pregnancy the IgM responses may be attenuated. Alcohol use during pregnancy may increase IgM responses to phosphatidylinositol $(\mathrm{Pi})$. Increased IgM-mediated autoimmune responses directed against NO-adducts and especially NOcysteinyl are associated with lifetime major depressive disorder (MDD). Tryptophan catabolite (TRYCAT) pathway activity is regulated by many processes including bacterial translocation and lifetime histories of premenstrual syndrome (PMS) and MDD (upregulation), while different factors may downregulate TRYCAT pathway activity, namely IgM-mediated natural autoimmune responses to malondialdehyde (MDA) and myristic acid (MA) (possibly via natural regulatory effects), hypernitrosylation (possibly by inhibiting indoleamine-2,3dioxygenase) and C-reactive protein (CRP) (possibly through its anti-inflammatory effects).

Acknowledgements This research has been supported by the Ratchadaphiseksomphot Endowment Fund 2013 of Chulalongkorn University (CU-56-457-HR) and IDRPHT, Talence, France.

Author contributions CR and MM made the design of the study. Participants were recruited and screened by CR. Biomarker assays were performed by MG and SD. All authors contributed equally to the writing up of the paper. All authors agreed upon the final version of the paper.

\section{Compliance with ethical standards}

Conflict of interest The authors have no conflict of interest with any commercial or other association in connection with the submitted article.

\section{References}

Abedian Z, Soltani N, Mokhber N, Esmaily H (2015) Depression and anxiety in pregnancy and postpartum in women with mild and severe preeclampsia. Iran J Nurs Midwifery res 20(4):454-459

Adam-Vizi V (2005) Production of reactive oxygen species in brain mitochondria: contribution by electron transport chain and non-electron transport chain sources. Antioxid Redox Signal 7(9-10):1140-1149

Albano E (2006) Alcohol, oxidative stress and free radical damage. Proc Nutr Soc 65(3):278-290

Anderson G, Maes M (2014) Oxidative/nitrosative stress and immunoinflammatory pathways in depression: treatment implications. Curr Pharm Des 20(23):3812-3847

Anderson G, Maes M (2016) How immune-inflammatory processes link CNS and psychiatric disorders: classification and treatment implications. CNS Neurol Disord Drug Targets

Anderson G, Berk M, Dean O, Moylan S, Maes M (2014a) Role of immune-inflammatory and oxidative and nitrosative stress pathways in the etiology of depression: therapeutic implications. CNS Drugs 28(1):1-10

Anderson G, Berk M, Maes M (2014b) Biological phenotypes underpin the physio-somatic symptoms of somatization, depression, and chronic fatigue syndrome. Acta Psychiatr Scand 129(2):83-97

Bayrampour H, Salmon C, Vinturache A, Tough S (2015) Effect of depressive and anxiety symptoms during pregnancy on risk of obstetric interventions. J Obstet Gynaecol Res

Boullerne AI, Petry KG, Meynard M, Geffard M (1995) Indirect evidence for nitric oxide involvement in multiple sclerosis by characterization of circulating antibodies directed against conjugated Snitrosocysteine. J Neuroimmunol 60(1-2):117-124

Boullerne A, Petry KG, Geffard M (1996) Circulating antibodies directed against conjugated fatty acids in sera of patients with multiple sclerosis. J Neuroimmunol 65(1):75-81

Boullerne AI, Rodriguez JJ, Touil T, Brochet B, Schmidt S, Abrous ND, Le Moal M, Pua JR, Jensen MA, Mayo W, Arnason BG, Petry KG (2002) Anti-S-nitrosocysteine antibodies are a predictive marker for demyelination in experimental autoimmune encephalomyelitis: implications for multiple sclerosis. J Neurosci 22(1):123-132

Challis JR, Lockwood CJ, Myatt L, Norman JE, Strauss JF 3rd, Petraglia F (2009) Inflammation and pregnancy. Reprod Sci 16(2):206-215

Chedid A, Chadalawada KR, Morgan TR, Moritz TE, Mendenhall CL, Hammond JB, Emblad PW, Cifuentes DC, Kwak JW, Gilman-Sachs 
A (1994) Phospholipid antibodies in alcoholic liver disease. Hepatology 20(6):1465-1471

Czarny P, Kwiatkowski D, Toma M, Gałecki P, Orzechowska A, Bobińska K, Bielecka-Kowalska A, Szemraj J, Berk M, Anderson G, Śliwiński T (2016) Single-nucleotide polymorphisms of genes involved in repair of oxidative DNA damage and the risk of recurrent depressive disorder. Med Sci Monit 22:4455-4474

Del Rio D, Stewart AJ, Pellegrini N (2005) A review of recent studies on malondialdehyde as toxic molecule and biological marker of oxidative stress. Nutr Metab Cardiovasc Dis 15(4):316-328

Duleu S, Mangas A, Sevin F, Veyret B, Bessede A, Geffard M (2010) Circulating antibodies to IDO/THO pathway metabolites in Alzheimer's disease. Int J Alzheimers Dis 2010:501541

Eyre HA, Papps E, Baune BT (2013) Treating depression and depressionlike behavior with physical activity: an immune perspective. Front Psychiatry 4(4):3

Fialová L, Kalousová M, Soukupová J, Malbohan I, Krofta L, Mikulíková L, Horejsová H, Stípek S, Zima T (2003) Levels of advanced oxidation protein products (AOPP) in the first trimester of pregnancy. Sb Lek 104(1):95-102

Frostegård J (2013) Immunity, atherosclerosis and cardiovascular disease. BMC Med 11:117

Gałecki P, Gałecka E, Maes M, Chamielec M, Orzechowska A, Bobińska K, Lewiński A, Szemraj J (2012) The expression of genes encoding for COX-2, MPO, iNOS, and sPLA2-IIA in patients with recurrent depressive disorder. J Affect Disord 138(3):360-366

Geffard M, Bodet D, Martinet Y, Dabadie MP (2002) Detection of the specific IgM and IgA circulating in sera of multiple sclerosis patients: interest and perspectives. Immuno-Analyse \& Biology Specification 17:302-310

Geffard M, Bodet D, Dabadie MP, Arnould L (2003) Identification of antibodies in sera of breast cancer patients. Immuno-Analyse \& Biologie Special 18:248-253

Ghaneei A, Yassini S, Ghanei ME, Shojaoddiny-Ardekani A (2015) Increased serum oxidized low-density lipoprotein levels in pregnancies complicated by gestational diabetes mellitus. Iran J Reprod med 13(7):421-424

Hucke C, MacKenzie CR, Adjogble KD, Takikawa O, Däubener W (2004) Nitric oxide-mediated regulation of gamma interferoninduced bacteriostasis: inhibition and degradation of human indoleamine 2,3-dioxygenase. Infect Immun 72(5):2723-2730

Kanchanatawan B, Sirivichayakul S, Ruxrungtham K, Carvalho AF, Geffard M, Anderson G, Maes M (2017) Deficit schizophrenia is characterized by defects in IgM-mediated responses to tryptophan catabolites (TRYCATs): a paradigm shift towards defects in natural self-regulatory immune responses coupled with mucosa-derived TRYCAT pathway activation. Mol Neurobiol

Kittirattanapaiboon P, Khamwongpin M (2005) The Validity of the Mini International Neuropsychiatric Interview (M.I.N.I.)- Thai Version. J Mental Health Thai 13:125-135

Koren O, Goodrich JK, Cullender TC, Spor A, Laitinen K, Bäckhed HK, Gonzalez A, Werner JJ, Angenent LT, Knight R, Bäckhed F, Isolauri E, Salminen S, Ley RE (2012) Host remodeling of the gut microbiome and metabolic changes during pregnancy. Cell 150(3):470-480

Liang YL, Zhang ZH, Liu XJ, Liu XQ, Tao L, Zhang YF, Wang H, Zhang C, Chen X, Xu DX (2012) Melatonin protects against apoptosisinducing factor (AIF)-dependent cell death during acetaminopheninduced acute liver failure. PLoS One 7(12):e51911

Maes M, Kubera M, Leunis JC (2008) The gut-brain barrier in major depression: intestinal mucosal dysfunction with an increased translocation of LPS from gram negative enterobacteria (leaky gut) plays a role in the inflammatory pathophysiology of depression. Neuroendocrinol Lett 29:117-124

Maes M, Mihaylova I, Kubera M, Leunis JC, Geffard M (2011a) IgMmediated autoimmune responses directed against multiple neoepitopes in depression: new pathways that underpin the inflammatory and neuroprogressive pathophysiology. J Affect Disord 135(1-3):414-418

Maes M, Galecki P, Chang YS, Berk M (2011b) A review on the oxidative and nitrosative stress (O\&NS) pathways in major depression and their possible contribution to the (neuro)degenerative processes in that illness. Prog Neuro-Psychopharmacol Biol Psychiatry 35(3): 676-692

Maes M, Mihaylova I, Kubera M, Leunis JC, Twisk FN, Geffard M (2012a) IgM-mediated autoimmune responses directed against anchorage epitopes are greater in Myalgic encephalomyelitis/chronic fatigue syndrome (ME/CFS) than in major depression. Metab Brain Dis 27(4):415-423

Maes M, Song C, Yirmiya R (2012b) Targeting IL-1 in depression. Expert Opin Ther Targets 16(11):1097-1112

Maes M, Kubera M, Mihaylova I, Geffard M, Galecki P, Leunis JC, Berk M (2013a) Increased autoimmune responses against auto-epitopes modified by oxidative and nitrosative damage in depression: implications for the pathways to chronic depression and neuroprogression. J Affect Disord 149(1-3):23-29

Maes M, Kubera M, Leunis JC, Berk M, Geffard M, Bosmans E (2013b) In depression, bacterial translocation may drive inflammatory responses, oxidative and nitrosative stress (O\&NS), and autoimmune responses directed against O\&NS-damaged neoepitopes. Acta Psychiatr Scand 127(5):344-354

Manzo-Avalos S, Saavedra-Molina A (2010) Cellular and mitochondrial effects of alcohol consumption. Int J Environ Res Public Health 7(12):4281-4304

Martinez FO, Sica A, Mantovani A, Locati M (2008) Macrophage activation and polarization. Front Biosci 13:453-461

Martin-Subero M, Anderson G, Kanchanatawan B, Berk M, Maes M (2016) Comorbidity between depression and inflammatory bowel disease explained by immune-inflammatory, oxidative, and nitrosative stress; tryptophan catabolite; and gut-brain pathways. CNS Spectr 21(2):184-198

Miller AH, Maletic V, Raison CL (2009) Inflammation and its discontents: the role of cytokines in the pathophysiology of major depression. Biol Psychiatry 65(9):732-741

Mo X, Pi L, Yang J, Xiang Z, Tang A (2014) Serum indoleamine 2,3dioxygenase and kynurenine aminotransferase enzyme activity in patients with ischemic stroke. J Clin Neurosci 21(3):482-486

Mohamed TN (2014) Cardiovascular disease and pregnancy. In: Lange RA (ed) Cardiology. Medscape

Mold C, Clos TW (2013) C-reactive protein inhibits plasmacytoid dendritic cell interferon responses to autoantibody immune complexes. Arthritis Rheum 65(7):1891-1901

Mor G, Cardenas I (2010) The immune system in pregnancy: a unique complexity. Am J Reprod Immunol 63(6):425-433

Morris G, Maes M (2013) Myalgic encephalomyelitis/chronic fatigue syndrome and encephalomyelitis disseminata/multiple sclerosis show remarkable levels of similarity in phenomenology and neuroimmune characteristics. BMC Med 11:205

Morris G, Berk M, Klein H, Walder K, Galecki P, Maes M (2016a) Nitrosative stress, Hypernitrosylation, and autoimmune responses to Nitrosylated proteins: new pathways in Neuroprogressive disorders including depression and chronic fatigue syndrome. Mol Neurobiol

Morris G, Carvalho AF, Anderson G, Galecki P, Maes M (2016b) The many Neuroprogressive actions of tryptophan catabolites (TRYCATs) that may be associated with the pathophysiology of neuro-immune disorders. Curr Pharm Des 22(8):963-977

Moylan S, Berk M, Dean OM, Samuni Y, Williams LJ, O'Neil A, Hayley AC, Pasco JA, Anderson G, Jacka FN, Maes M (2014) Oxidative \& nitrosative stress in depression: why so much stress? Neurosci Biobehav Rev 45:46-62

Nicholson L, Lecour S, Wedegärtner S, Kindermann I, Böhm M, Sliwa K (2016) Assessing perinatal depression as an indicator of risk for 
pregnancy-associated cardiovascular disease. Cardiovasc J Afr 27(2):119-122

Pitanupong J, Liabsuetrakul T, Vittayanont A (2007) Validation of the Thai Edinburgh postnatal depression scale for screening postpartum depression. Psychiatry Res 149(1-3):253-259

Prasad AS (2007) Zinc: mechanisms of host defense. J Nutr 137(5):13451349

Pryor WA, Stanley JP (1975) Letter: a suggested mechanism for the production of malondialdehyde during the autoxidation of polyunsaturated fatty acids. Nonenzymatic production of prostaglandin endoperoxides during autoxidation. J org Chem 40(24):3615-3617

Rahman M, Sing S, Golabkesh Z, Fiskesund R, Gustafsson T, Jogestrand T, Frostegård AG, Hafström I, Liu A, Frostegård J (2016) IgM antibodies against malondialdehyde and phosphorylcholine are together strong protection markers for atherosclerosis in systemic lupus erythematosus: regulation and underlying mechanisms. Clin Immunol 166-167:27-37

Ridker PM, Lüscher TF (2014) Anti-inflammatory therapies for cardiovascular disease. Eur Heart J 35(27):1782-1791

Ronis MJJ, Lindros KO, Ingelman-Sundberg M (1996) The CYP2E family. In: Ioannides C (ed) Cytochromes P450: metabolic and toxicological aspects. CRC Press, Boca Raton, pp 211-239

Roomruangwong C, Kanchanatawan B, Sirivichayakul S, Anderson G, Carvalho AF, Duleu S, Geffard M, Maes M (2016) IgA/IgM responses to tryptophan and tryptophan catabolites (TRYCATs) are differently associated with prenatal depression, physio-somatic symptoms at the end of term and premenstrual syndrome. Mol Neurobiol

Schwartz-Albiez R, Monteiro RC, Rodriguez M, Binder CJ, Shoenfeld Y (2009) Natural antibodies, intravenous immunoglobulin and their role in autoimmunity, cancer and inflammation. Clin Exp Immunol 158(Suppl 1):43-50
Spielberger CD, Vagg PR (1984) Psychometric properties of the STAI: a reply to Ramanaiah, Franzen, and Schill. J Pers Assess 48(1):95-97

Thapinta D (1991) Reduction of anxiety of staff nurses working with AIDS patients through cognitive Reconstructuring andMindfulness training. In: Educational Psychology. Chulalongkorn University, Bangkok, p 154

Thiele JR, Habersberger J, Braig D, Schmidt Y, Goerendt K, Maurer V, Bannasch H, Scheichl A, Woollard KJ, von Dobschütz E, Kolodgie F, Virmani R, Stark GB, Peter K, Eisenhardt SU (2014) Dissociation of pentameric to monomeric $\mathrm{C}$-reactive protein localizes and aggravates inflammation: in vivo proof of a powerful proinflammatory mechanism and a new anti-inflammatory strategy. Circulation 130(1):35-50

Tsuboi H, Watanabe M, Kobayashi F, Kimura K, Kinae N (2013) Associations of depressive symptoms with serum proportions of palmitic and arachidonic acids, and $\alpha$-tocopherol effects among male population-a preliminary study. Clin Nutr 32(2):289-293

Ulrich C, Quillici DR, Schegg K, Woolsey R, Nordmeier A, Buxton IL (2012) Uterine smooth muscle S-nitrosylproteome in pregnancy. Mol Pharmacol 81(2):143-153

Vacharaporn K, Pitanupong J, Samangsri N (2003) Development of the Edinburgh postnatal depression scale Thai version. Journal of Mental Health of Thailand 11(3):164-169

Wakabayashi T (2002) Megamitochondria formation - physiology and pathology. J Cell Mol Med 6(4):497-538

Zhang HH, Feng L, Wang W, Magness RR, Chen DB (2012) Estrogenresponsive nitroso-proteome in uterine artery endothelial cells: role of endothelial nitric oxide synthase and estrogen receptor- $\beta$. J Cell Physiol 227(1):146-159

Zheng P, Chen JJ, Huang T, Wang MJ, Wang Y, Dong MX, Huang YJ, Zhou LK, Xie P (2013) A novel urinary metabolite signature for diagnosing major depressive disorder. J Proteome Res 12(12):5904-5911 